\title{
Water temperature effect on upward air-water flow in a vertical pipe: Local measurements database using four-sensor conductivity probes and LDA
}

\author{
G. Monrós-Andreu ${ }^{1}$, S. Chiva ${ }^{1, *}$, R. Martínez-Cuenca ${ }^{1}$, S. Torró ${ }^{1}$, J. E. Juliá ${ }^{1}$, L. Hernández ${ }^{1}$ and R. Mondragón ${ }^{1}$ \\ ${ }^{1}$ Department of Mechanical Engineering and Construction, Universitat Jaume I, Campus Riu Sec, E-12071, Castellón, \\ Spain.
}

\begin{abstract}
Experimental work was carried out to study the effects of temperature variation in bubbly, bubbly to slug transition. Experiments were carried out in an upward air-water flow configuration. Four sensor conductivity probes and LDA techniques was used together for the measurement of bubble parameters. The aim of this paper is to provide a bubble parameter experimental database using four-sensor conductivity probes and LDA technique for upward air-water flow at different temperatures and also show transition effect in different temperatures under the boiling point.
\end{abstract}

\section{Introduction}

Two-phase flows have been studied extensively. These flows can be found in many industrial applications as chemical reactors, nuclear energy production and oil recovery. Many experimental, theoretical and numerical works have been conducted for different pipe sizes, flow rates and fluid properties.

One of the most important key issues in the two-phase flow analysis is the existence of multidimensional interfaces between both phases. The correct behaviour prediction of these interfaces, and its quantification, is one of the frontier ${ }^{\mathrm{a}} \mathrm{s}$ in the theoretical and experimental studies of this kind of flow, and up to now, there is not an effective technique and methodology for the multidimensional interface characterization in two-phase flow measurement. Then, experimental works play a very important role in the development of new theoretical models and measurement devices.

The basic structure of a two-phase flow can be characterized by three fundamental parameters. These are the void fraction, the Sauter mean diameter (for bubbly flow mainly) and the interfacial area concentration (IAC) [1]. The void fraction expresses the phase distribution and it is a required parameter for the hydrodynamic and thermal design in several industrial processes. The interfacial area concentration describes the available area for the interfacial transfer of mass, momentum and energy, and it is a required parameter for a two-fluid formulation, and the key for most of the industrial applications. The Sauter mean diameter is defined as the diameter of a sphere that has the same volume per surface area ratio as the bubble, and as de interfacial area concentration, is especially important in calculations where the active surface area is important. An accurate knowledge of these parameters is necessary for any twophase flow analyses.

"Corresponding author: schiva@uji.es
The use of needle probes as an intrusive method to measure is a well established method for the investigation of multiphase flows. Different measuring techniques can be employed for the needle probes. The most known techniques are based on conductivity, capacitance or optical measurements. Based on the phase identification, these probes can provide information about void fraction, IAC, bubble size, frequency and velocity using simple physical principles.

Measurements of interfacial area in bubbly flow have been done by using double-sensor conductivity probes by Kataoka et al.[2], Hibiki and Ishii [3], Wu and Ishii [4] and Hibiki et al. [5], and four-sensor conductivity probes by Revankar and Ishii [6], Kim, et al. [7]. Furthermore, Hibiki and Ishii [8], Hibiki et al. [9], have developed interfacial area transport equation (IATE), that was formulated by mechanicastically modeling of the physical processes that govern the creation and destruction of interfacial area. At present, more experimental data on interfacial area concentration are needed in order to test the models in modern computerized fluid dynamics (CFD) codes.

The way in which the phases distribute across the pipe have a fundamental influence on important operating parameters such as the friction and heat transfer coefficients. The phase distribution was mapped experimentally by Taitel et al. [10] and different flow regimes were identified such as bubbly, slug, churn and annular. Some experimental correlations have been proposed to predict the transition between flow regimes; however, their dependence on specific flow parameters compromises their general applicability.

It has been observed that for the case of bubbly flows, the bubbles may accumulate preferentially either near the walls (a peak of the gas volume fraction is observed near the wall, i.e., a wall peak) or around the center (a core peak). Serizawa and Kataoka [11] and Zun [12] identified these distinct radial distribution patterns associated to area-averaged void fraction. The pattern classification 
proposed was: wall peak, characterized by a sharp peak of high void fraction near the wall and a 'valley' at the channel center with smaller void fraction; and core peak, for which a peak appears around the center of the channel only. The void fraction distribution is correlated with the flow regime as well as some local parameters as interfacial area concentration, gas fraction and superficial velocities. Although there have been some studies that address these issues, S. Méndez-Diaz et al. [13], the mechanisms which determine the phase distribution across the pipe are still partially understood.

A survey of the literature reveals that most investigations of gas/liquid two-phase flow simulation and regime recognition have not considered temperature effects. The present work aims to establish experimentally the effect of temperature on the bubble parameters at different temperatures, particularly around transition from bubbly to slug zone, and provide experimental data for future researches. This experimental data is obtained with two-phase flow at different axial positions along a vertical pipe using foursensor conductivity probes and Laser Doppler Anemometry (LDA) combined measurements.

The experimental data at different temperatures will help to see how the flow structure changes as the airwater system approaches to transition zone. However, much more information will be needed in order to completely characterize two-phase flow structure at different temperatures.

\section{Experimental facility}

The experimental loop is schematically illustrated in figure. 1. The test section was a round transparent tube made of Plexiglas ${ }^{\circledR}, 52 \mathrm{~mm}$ inner diameter and $5500 \mathrm{~mm}$ length. The working fluids in operation were air and water. The water was circulated in the loop by a pair of centrifugal pumps, controlled with a frequency controller device. The air was introduced into the test section through a mixing chamber. Both the flow rates of air and water were measured by flow meters. The bubbles, with diameters ranging from 1 to $3 \mathrm{~mm}$, were generated by a sparger, with an average porosity of 40 microns, located in the base of mixing chamber. Pressure transducers (P0$\mathrm{P} 4)$ and temperature sensors (T0-T3) are installed in order to register water and air. The superficial velocity of the liquid phase is measured using a magnetic flow meter (Badger model M100), which provides the superficial velocity of the liquid phase at the inlet of the column test section. Injected air superficial velocity is measured and controlled with a Bronckhorst EL-FLOW flow controller.

In order to control water temperature it is necessary to place a heat exchanger (Euroklimat R407C SMART $400 / 30 / 50$ ) connected to the water tank so that the system temperature is maintained at a constant temperature in the range between 15 to $37^{\circ} \mathrm{C}$. Experimental tests are performed at different temperatures, it requires temperature control in the air inlet section (T0) and along the water circuit (T1-T3). In each measurement port pressure sensors are installed (P1-P4) and also before mixing chamber (P0). These sensors have ranges of $0-1$ bar to the bottom port, and $0-250 \mathrm{mBar}$ for the other two

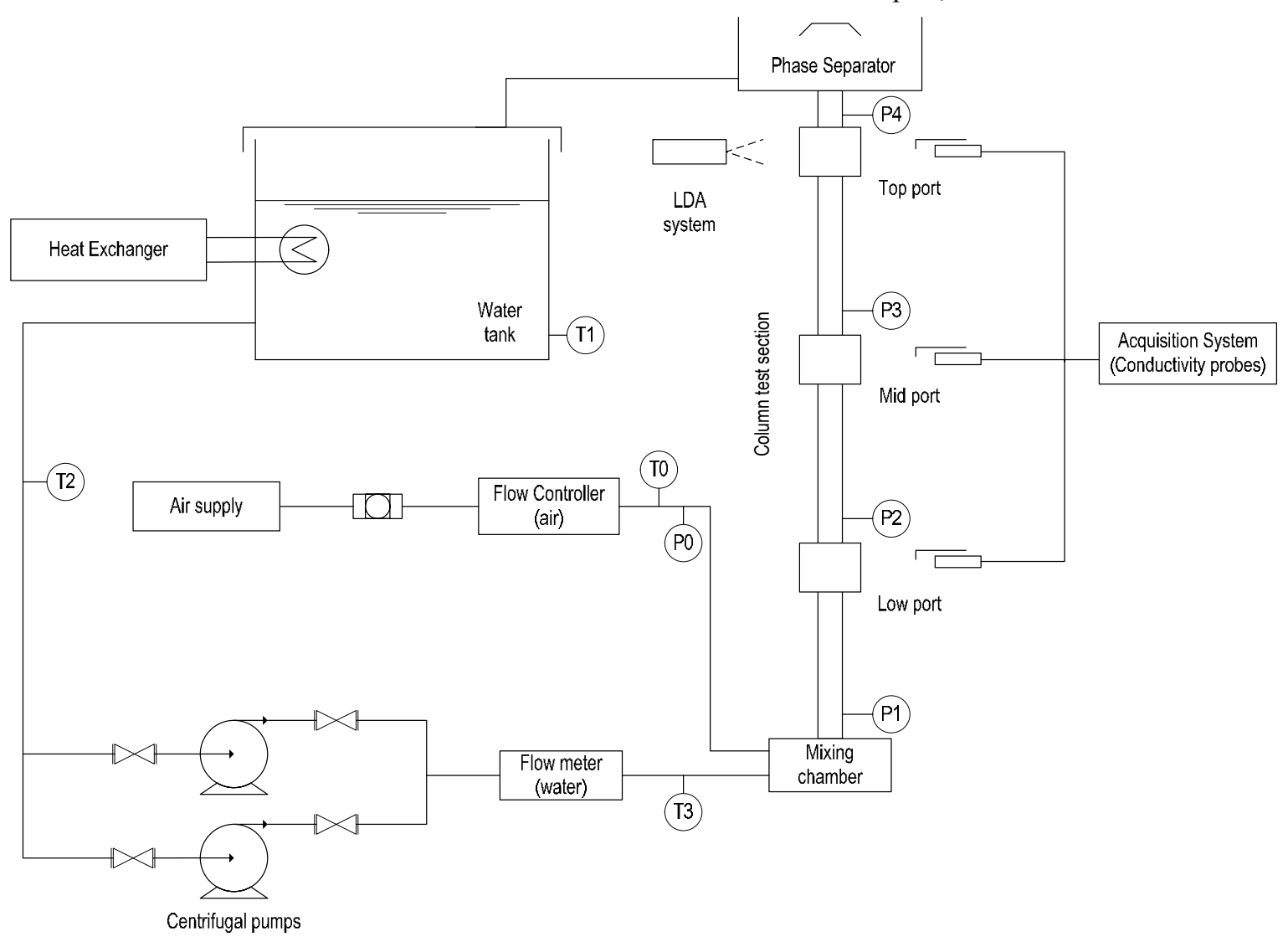

Fig 1. General overview of the experimental facility 
ports.

The interfacial area concentration, void fraction and bubble chord length were measured using four-sensor conductivity probe. The local flow measurements using a four-sensor conductivity probe were carried out at the axial locations of $1166 \mathrm{~mm}$ (Low port, $\mathrm{L} / \mathrm{D}=22.4$ ), 3176 $\mathrm{mm}$ (Mid port, $\mathrm{L} / \mathrm{D}=61$ ) and $5131 \mathrm{~mm}$ (Top port, $\mathrm{L} / \mathrm{D}=98.7)$.

In order to measure the liquid velocity we use LDA. The LDA equipment consists of a $0.5 \mathrm{~W} \mathrm{Ar}+$ Ominichrome laser, Dantec Fiberflow beam separator, Dantec FVA 58N40 processor and a PC using the software Floware for data acquisition. The measurements by LDA system were performed at the axial location of $5070 \mathrm{~mm}(\mathrm{~L} / \mathrm{D}=97.5)$ from the bottom of the test section.

\section{Four sensor conductivity probes}

\subsection{Methodology}

The four-sensor probe measurement system is schematically shown in figure 2.

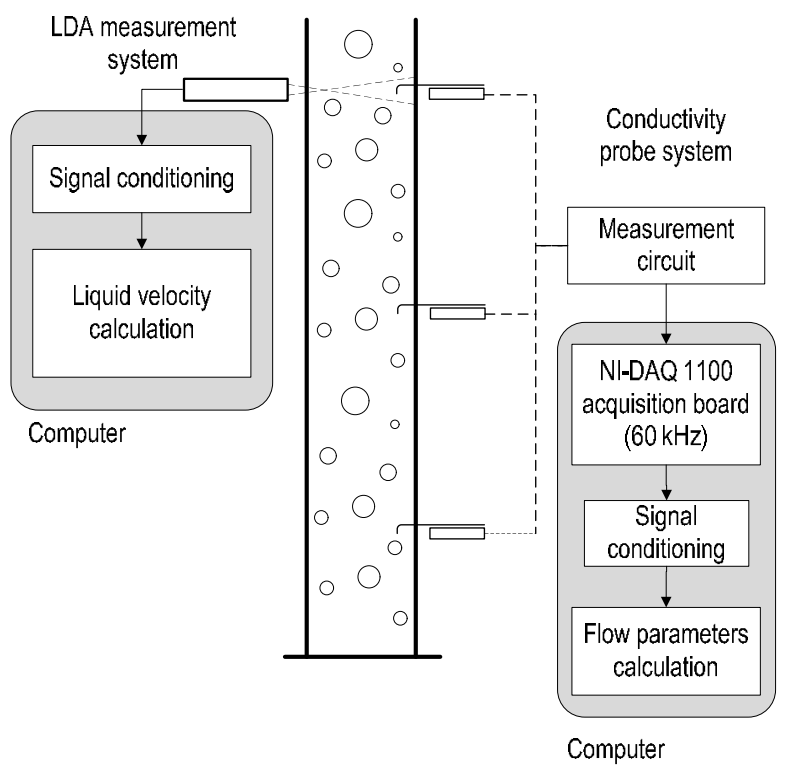

Fig 2. LDA and conductivity probe systems

The measurement system consisted of three mounted four-sensor conductivity probes, mechanical traversers, a measurement circuit, a digital high-speed acquisition board, and the software used to signal processing. The four-sensor conductivity probe was attached to the mechanical traverser mounted on a specially designed flange, and it could be moved along the radial direction of the test section using controlled step motors. The measurement circuit was used to measure the potential difference between the exposed tip and the grounded terminal. A high-speed NI SCXI-1000 acquisition board and a $\mathrm{PC}$ were used to acquire the voltage signal of the four-sensor probe, with the help of a control program developed under NI LabView software environment. This control program is also used for acquire the data from pressure, temperature and flow transducers and control the centrifugal pumps and air flow controller in order to prepare a run test. The sampling frequency was set 60 $\mathrm{kHz}$ for each conductivity probe, and the sampling time was 30 seconds. Mechanical traverser, is also managed with NI Labview control software in order to move simultaneously and with precision the three conductivity probes through radial positions inside the pipe.

The four- sensor probe is basically a phase identifier. It consists of four sensors made of insulated copper, with a diameter of $0.25 \mathrm{~mm}$. The vertical distance between main and auxiliary tips was about $1.5 \mathrm{~mm}$. The probe is connected to a power supply with a fixed voltage, due to the large difference in conductivity between the liquid phase and the gas phase, the impedance signal acquired rises sharply when a bubble passes through one of the sensor tips.

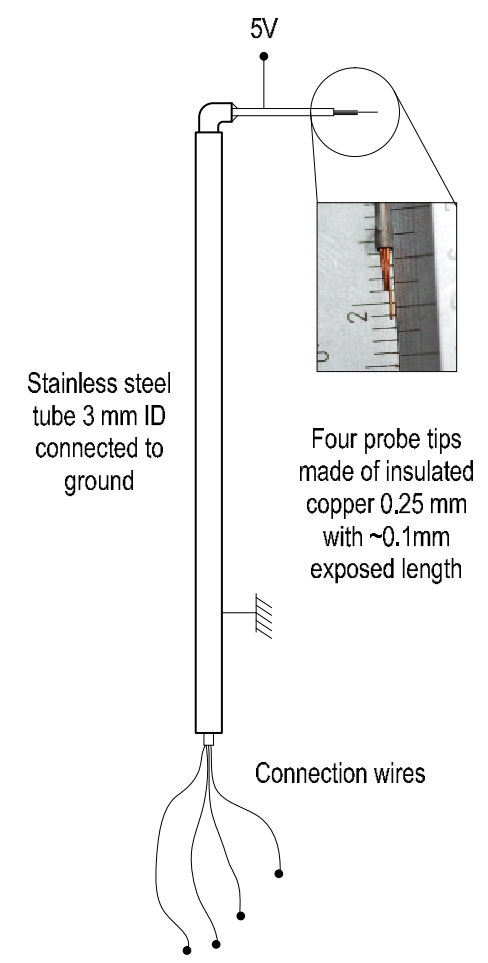

Fig 3. Four-sensor conductivity probe schema.

\subsection{Signal processing}

When the probe sensor is surrounded by liquid, a lower voltage is put out; and when the probe sensor contacts with gas, a higher voltage is obtained. But due to the finite size of each sensor and the time delay needed to wet or rewet the sensor tips, the output signal of the foursensor probe differed from ideal two-state square-wave. A suitable signal processing technique is therefore necessary to extract the required information from the raw signal. In the present work, processing software in Matlab platform has been developed in order to regenerate the ideal square-wave signal and process it in order to calculate main bubble parameters.

The processing software acts as a phase identifier based on signal level. First the signal is filtered and normalized. After that the code recognizes bubbles start by two different methods: recursive fitting algorithm or direct use of an auxiliary treshold (if the signal noise near rise point is too high for using the recursive fit). Finally, 
bubbles ends are computed when signal falls after a relative maximum of the signal.

Signals before and after processing using this method are illustrated in figure 4.

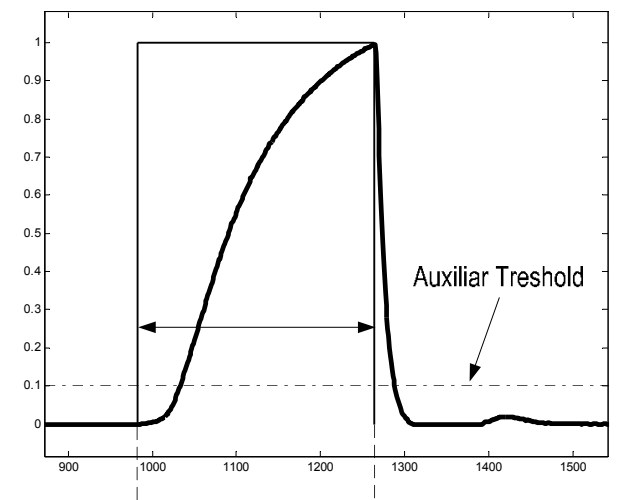

Bubble start (Ts) Bubble end (Te)

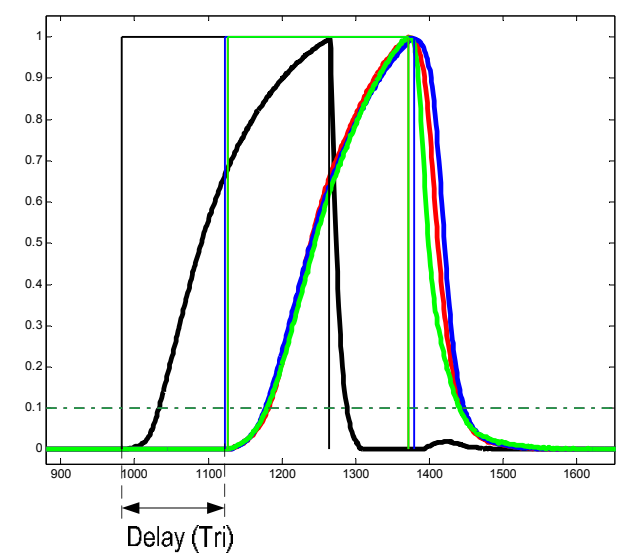

Fig 4. Signal processing.

From the square-wave signal the number of bubbles that hit the sensor can be measured by counting the number of pulses in the signal. The three components of interfacial velocity of each interface can be obtained by using the distance to the different tips of the four-sensor probe, and time delay between the upstream and downstream signal $\left(T_{r i}\right)$ From the local instant formulation of the two-fluid model, the local timeaveraged void fraction can be expressed as the ratio between the accumulated pulse widths of the upward or downward sensor $\left(T_{e}-T_{s}\right)$ and the total sampling time during the sampling period.

Local parameters of the two-phase flows can be obtained from two types of information: the residence time of the gas phase in the probe and signal delay recoded between different paired tips. This allows us to record the Chord length, void fraction and average interfacial speed as main parameters directly from acquired data. Once these three parameters are obtained and interfacial area concentration obtained, Sauter mean diameter can be indirectly calculated. The four-sensor conductivity probe method can predict the IAC without any assumptions of bubble shape or interfacial motion for bubbles having a large size relative to the probe.

Delhaye and Bricard [1] pointed out that the structure of a bubbly two-phase flow can be characterized by two of the three of following parameters: the interfacial area concentration (IAC), the void fraction and the Sauter median diameter. The IAC (a) is defined by the total interface area per unit mixture volume. According to Ishii [14], the local time-averaged IAC at fixed point in space $\mathrm{x} 0$ is given by:

$$
\bar{a}^{t}\left(x_{0}\right)=\frac{1}{\Omega} \sum_{t} \frac{1}{\left|V_{l i} \cdot n_{l i}\right|}
$$

Where $\Omega, l, v_{i l}, n_{i l}$ denote the time interval for averaging, the interface of bubble, the velocity vector of considered interface, the surface normal unit vector of the considered interface at $\mathrm{x} 0$ when it passes through $\mathrm{x} 0$.

Shen et al., were the first to propose a theoretical proof based on their interfacial measurement theorem for multi-sensor probes, by using vector analysis and pointed out that a four-sensor probe could measure the interfacial velocity component in the interfacial direction. Their methodology enabled the interfacial area concentration measurement and the instantaneous interfacial direction measurement in multi-dimensional two-phase flow. Their expression for the interfacial area concentration measurement is:

$$
\overline{\mathrm{a}}^{\mathrm{t}}\left(\mathrm{x}_{0}\right)=\frac{1}{\Omega} \sum_{\mathrm{i}=1}^{\mathrm{N}_{\mathrm{ti}}} \frac{\sqrt{\mathrm{A}_{01 \mathrm{i}}^{2}+\mathrm{A}_{02 \mathrm{i}}^{2}+\mathrm{A}_{03 \mathrm{i}}^{2}}}{\left|\mathrm{~A}_{0}\right|}
$$

Where $\Omega$ is the time interval for averaging, $N_{t}$ the total number of interfaces that hit the sensor during the interval time, and $A_{0}, A_{1}, A_{2}, A_{3}$ are determinants only dependant of geometric distribution of the sensor tips and time delay between interfaces.

More details about expression 3 can be found in Shen et al. [15].

Sauter mean diameter $\left(d_{S M}\right)$, given by the ratio of the volume and surface area of a typical bubble, can be calculated as:

$$
\mathrm{d}_{\mathrm{SM}}=\frac{6 \cdot \alpha}{\mathrm{a}}
$$

Where $\alpha$ is the void fraction, total gas phase per unit mixture and $a$ is the interfacial area concentration.

Using the information of processed signal several bubble parameters has been calculated:

- Local time-averaged void fraction.

- Local time-averaged IAC.

- Local Chord length distributions.

- Local interfacial velocity.

- Local number of bubbles and size based classification.

In order to store as much information as possible, probability distributions has been obtained. For each radial point interfacial velocity is calculated as mean value of PDF that fits interfacial velocity distribution. For interfacial velocity, lognormal distribution has been considered. Figure 5 shows an example of interfacial velocities distributions for a one axial position. 

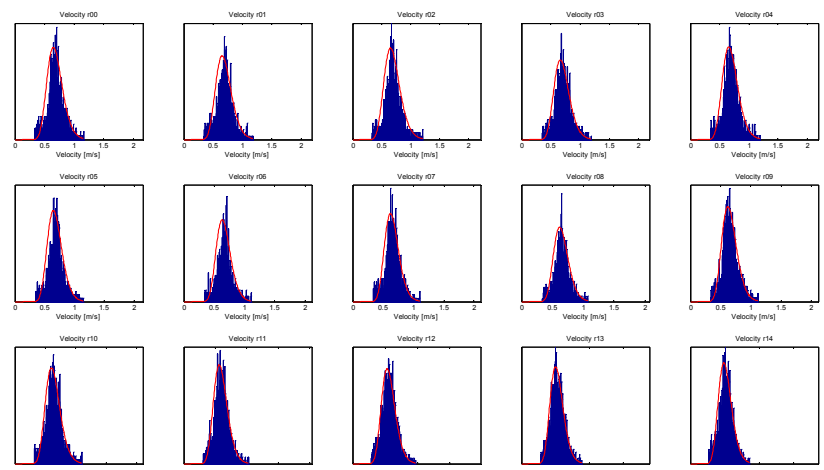

Fig 5. Example of interfacial velocity distribution for an axial position. Case $j l=0.5 \mathrm{~m} / \mathrm{s}, j g=0.05 \mathrm{~m} / \mathrm{s}, \mathrm{TC}$, and $\mathrm{L} / \mathrm{D}=61$.

For each radial point chord length is calculated as mean value of PDF that fits chord length distribution. For chord length, normal distribution has been considered. Figure 6 shows an example of Chord length distributions for a one axial position.
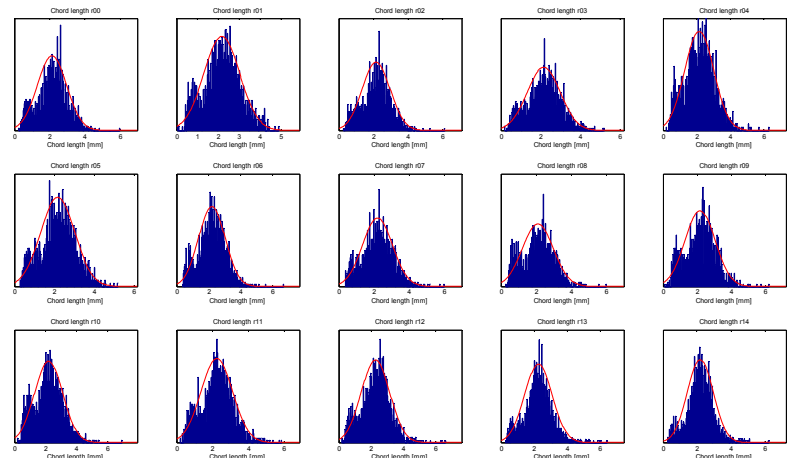

Fig 6. Example of Chord length distribution for an axial position. Case $j l=0.5 \mathrm{~m} / \mathrm{s}, j g=0.05 \mathrm{~m} / \mathrm{s}, \mathrm{TC}$ and $\mathrm{L} / \mathrm{D}=61$.

Detected bubbles are classified depending bubble diameter limit criteria proposed by Ishii et al. [16], using individual bubble interfacial velocity and chord length. Diameter limit for each different type of bubble are:

Table 1. Bubble diameter limit criteria.

\begin{tabular}{|c|c|c|}
\hline $\begin{array}{c}\text { Spherical } \\
\text { Bubbles }\end{array}$ & $\begin{array}{c}\text { Distorted } \\
\text { bubbles }\end{array}$ & $\begin{array}{c}\text { Cup-slug } \\
\text { bubbles }\end{array}$ \\
\hline$D_{\text {esf }}=4 \sqrt{\frac{2 \sigma}{g \Delta \rho} N_{\mu_{f}}^{1 / 3}}$ & $D_{\text {dist }}=4 \sqrt{\frac{\sigma}{g \Delta \rho}}$ & $D_{c a p_{M A x}}=40 \sqrt{\frac{\sigma}{g \Delta \rho}}$ \\
$N_{\mu_{f}}=\frac{\mu_{f}}{\left(\rho_{f} \sigma \sqrt{\frac{\sigma}{g \Delta \rho}}\right)^{1 / 2}}$ & & \\
\hline
\end{tabular}

\subsection{Experimental data}

Four-sensor conductivity probes data sets have been taken at different conditions:

- Superficial liquid velocities $j l: 0.5,1,2 \mathrm{~m} / \mathrm{s}$.

- $\quad$ Superficial gas velocities jg: $0,0.05,0.1$, $0.15,0.2,0.3 \mathrm{~m} / \mathrm{s}$.

- $\quad$ Temperatures: $15^{\circ} \mathrm{C}$ (TC), $21^{\circ} \mathrm{C}$ (TA) and $37^{\circ} \mathrm{C}(\mathrm{TH})$
- 15 radial measurement points at three axial positions $(\mathrm{L} / \mathrm{D}=22.4), \mathrm{L} / \mathrm{D}=61, \mathrm{~L} / \mathrm{D}=98.7)$.

The flow conditions have been chosen measuring the superficial liquid and air velocity and the average void fraction on $\mathrm{L} / \mathrm{D}=22.4$ for each condition. All the conditions (Table 2) are in the bubbly flow regime.

Table 2. Experimental flow conditions for conductivity probes.

\begin{tabular}{|c|c|c|c|c|c|c|c|c|c|c|c|}
\hline \multicolumn{4}{|c|}{$\begin{array}{c}\mathrm{jl} \\
0.5 \mathrm{~m} / \mathrm{s}\end{array}$} & \multicolumn{4}{|c|}{$\begin{array}{c}\mathrm{jl} \\
1 \mathrm{~m} / \mathrm{s}\end{array}$} & \multicolumn{4}{|c|}{$\begin{array}{c}\mathrm{jl} \\
2 \mathrm{~m} / \mathrm{s}\end{array}$} \\
\hline Nrun & $\begin{array}{c}\mathbf{j g} \\
{[\mathbf{m} / \mathbf{s}]}\end{array}$ & & $\begin{array}{c}\mathrm{T} \\
{\left[{ }^{\circ} \mathbf{C}\right]}\end{array}$ & & $\begin{array}{c}\mathbf{j g} \\
{[\mathbf{m} / \mathbf{s}]}\end{array}$ & $\begin{array}{c}\alpha \\
{[-]}\end{array}$ & & & $\begin{array}{c}\mathbf{j g} \\
{[\mathrm{m} / \mathrm{s}]}\end{array}$ & $\begin{array}{c}\alpha \\
{[-]}\end{array}$ & $\begin{array}{c}{ }^{\mathrm{T}} \\
{\left[{ }^{\circ} \mathbf{C}\right]}\end{array}$ \\
\hline Run01 & 0,05 & 0,06 & 16,52 & Run18 & $\overline{0,05}$ & 0,05 & 15,00 & Run35 & $\overline{0,10}$ & 0,05 & 15,87 \\
\hline Run02 & 0,10 & 0,13 & 18,96 & Run19 & 0,10 & 0,09 & 14,65 & Run36 & 0,20 & 0,10 & 16,27 \\
\hline Run03 & 0,15 & 0,19 & 17,98 & Run20 & 0,15 & 0,12 & 14,53 & Run37 & 0,25 & 0,13 & 16,57 \\
\hline Run04 & 0,20 & 0,24 & 17,13 & Run21 & 0,20 & 0,15 & 14,77 & Run 38 & 0,30 & 0,15 & 16,79 \\
\hline Run05 & 0,25 & 0,28 & 16,41 & Run22 & 0,25 & 0,19 & 14,79 & Run39 & 0,10 & 0,05 & 14,78 \\
\hline Run06 & 0,30 & 0,32 & 15,82 & Run 23 & 0,30 & 0,22 & 15,53 & Run 40 & 0,20 & 0,10 & 15,34 \\
\hline Run07 & 0,05 & 0,06 & 20,67 & Run24 & 0,05 & 0,05 & 23,08 & Run 41 & 0,30 & 0,13 & 15,75 \\
\hline Run08 & 0,10 & 0,13 & 20,64 & Run 25 & 0,10 & 0,09 & 23,38 & Run 42 & 0,35 & 0,15 & 16,06 \\
\hline Run09 & 0,15 & 0,19 & 20,60 & Run26 & 0,20 & 0,15 & 24,20 & Run 43 & 0,10 & 0,05 & 21,33 \\
\hline Run 10 & 0,20 & 0,24 & 20,57 & Run27 & 0,25 & 0,19 & 24,45 & Run44 & 0,15 & 0,07 & 21,60 \\
\hline Run11 & 0,30 & 0,31 & 20,56 & Run 28 & 0,30 & 0,22 & 23,66 & Run45 & 0,20 & 0,10 & 22,64 \\
\hline Run12 & 0,05 & 0,07 & 34,60 & Run29 & 0,05 & 0,05 & 35,83 & Run 46 & 0,30 & 0,13 & 21,42 \\
\hline Run13 & 0,10 & 0,13 & 35,77 & Run30 & 0,10 & 0,08 & 36,47 & Run 47 & 0,10 & 0,05 & 36,56 \\
\hline Run14 & 0,15 & 0,20 & 36,34 & Run31 & 0,15 & 0,13 & 36,52 & & 0,20 & 0,10 & 36,68 \\
\hline Run15 & 0,20 & 0,25 & 36,62 & Run32 & 0,20 & 0,17 & 36,71 & Run 49 & 0,25 & 0,13 & 36,55 \\
\hline Run16 & 0,25 & 0,27 & 36,38 & Run33 & 0,25 & 0,20 & 36,52 & Run50 & 0,30 & 0,15 & 36,46 \\
\hline Run17 & 0,30 & 0,27 & 36,67 & Run34 & 0,30 & 0,23 & 36,67 & Run51 & 0,10 & 0,05 & 36,54 \\
\hline & & & & & & & & Run52 & 0,20 & 0,10 & 36,46 \\
\hline & & & & & & & & Run53 & 0,25 & 0,13 & 36,45 \\
\hline & & & & & & & & & 0,30 & 0,15 & 36,7 \\
\hline
\end{tabular}

Experiments carried out are represented in the flow regime map proposed by Taitel et al [10] shown in figure 7 for a $50 \mathrm{~mm}$ pipe inner diameter.

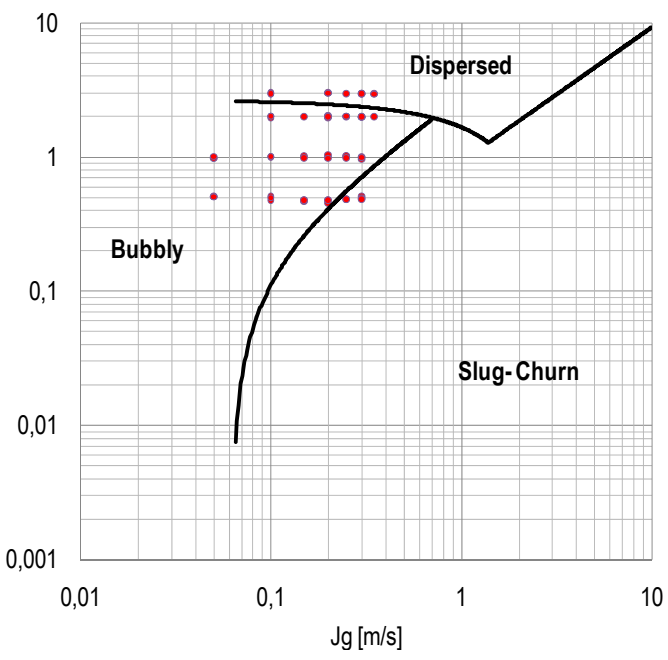

Fig 7. Flow regime map.

As example of the results obtained using our facility, Figure 8 shows experimental void fraction average profile data vs radial position for case $j l=1 \mathrm{~m} / \mathrm{s}$ and $j g=0.3$ at two different temperatures, TC (cool temperature, $15^{\circ} \mathrm{C}$ ) and $\mathrm{TH}$ (hot temperature, $37^{\circ} \mathrm{C}$ ). Effect of wall peak to core peak transition and the change in the bubble size radial distribution can be observed. 

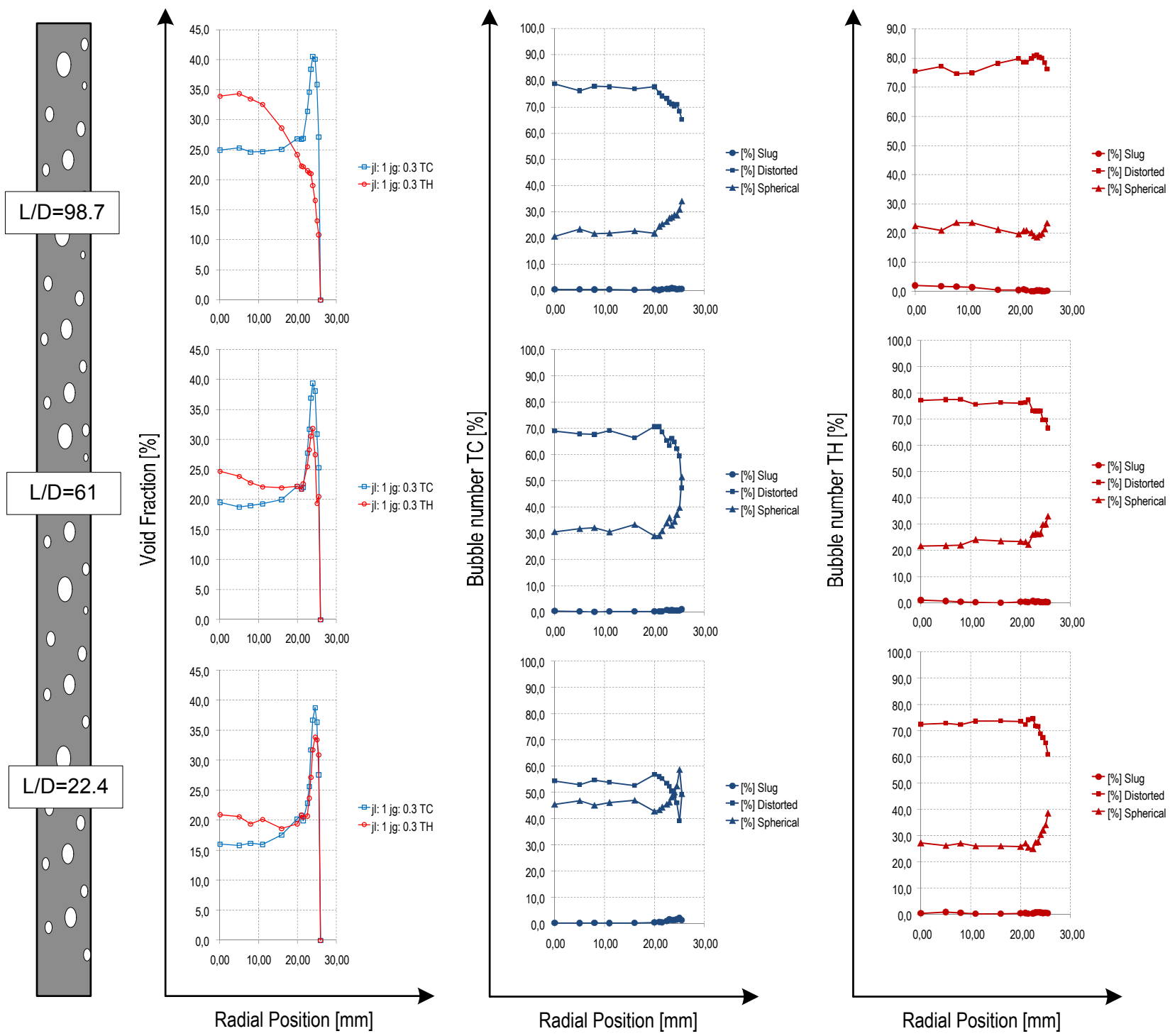

Fig 8. Void fraction and bubble size classification evolution for $\mathrm{jl}=1 \mathrm{~m} / \mathrm{s}, 15^{\circ}(\mathrm{TC})$ and $37^{\circ}(\mathrm{TH})$.

The local void fraction profile has a typical evolution of the pressure reduction. The peaks in the void fraction profile were located more or less at one diameter from the wall.

While the evolution of local profile along the pipe at TC maintain the wall peak configuration, same flow configuration at higher temperature $\mathrm{TH}$ presents a clear transition or core peak distribution at $\mathrm{L} / \mathrm{D}=98.7$.

In $\mathrm{TC}$ conditions distorted and spherical are the only bubble size observed, and as the pressure decreases along the pipe it is observed that the percentage of distorted bubbles grows to the detriment of the spherical one mainly due either to the coalescence effect and pressure reduction.

However in $\mathrm{TH}$ conditions clearly predominant percentage of distorted bubbles over the spherical. Due to larger size of those bubbles, it tends to move to the center of the pipe changing the void fraction profile to core peak at the top of the pipe. At $\mathrm{L} / \mathrm{D}=98.7$ slug bubbles were clearly detected $(2.1 \%$ over total number of bubbles at this radial position)).

It has been observed that a transition or core peak distribution appears when the percentage of slug bubbles computed in the center of the pipe over the total of computed bubbles is greater than $1 \%$.

Figures 9, 10 and 11 show some experimental data results obtained in our facility. Only the extreme values of $j g$ and $j l$ are shown with the aim to give a clear representation of the data most important found. General characteristics observed from experimental data:

- In the cases without clear core peak distribution, the cord length is quite uniform.

- In all the profiles IAC shows a similar behaviour of its respective void fraction profile if chord length is more or less uniform

- The interfacial velocity has a flat profile for cases with wall peak distribution. 

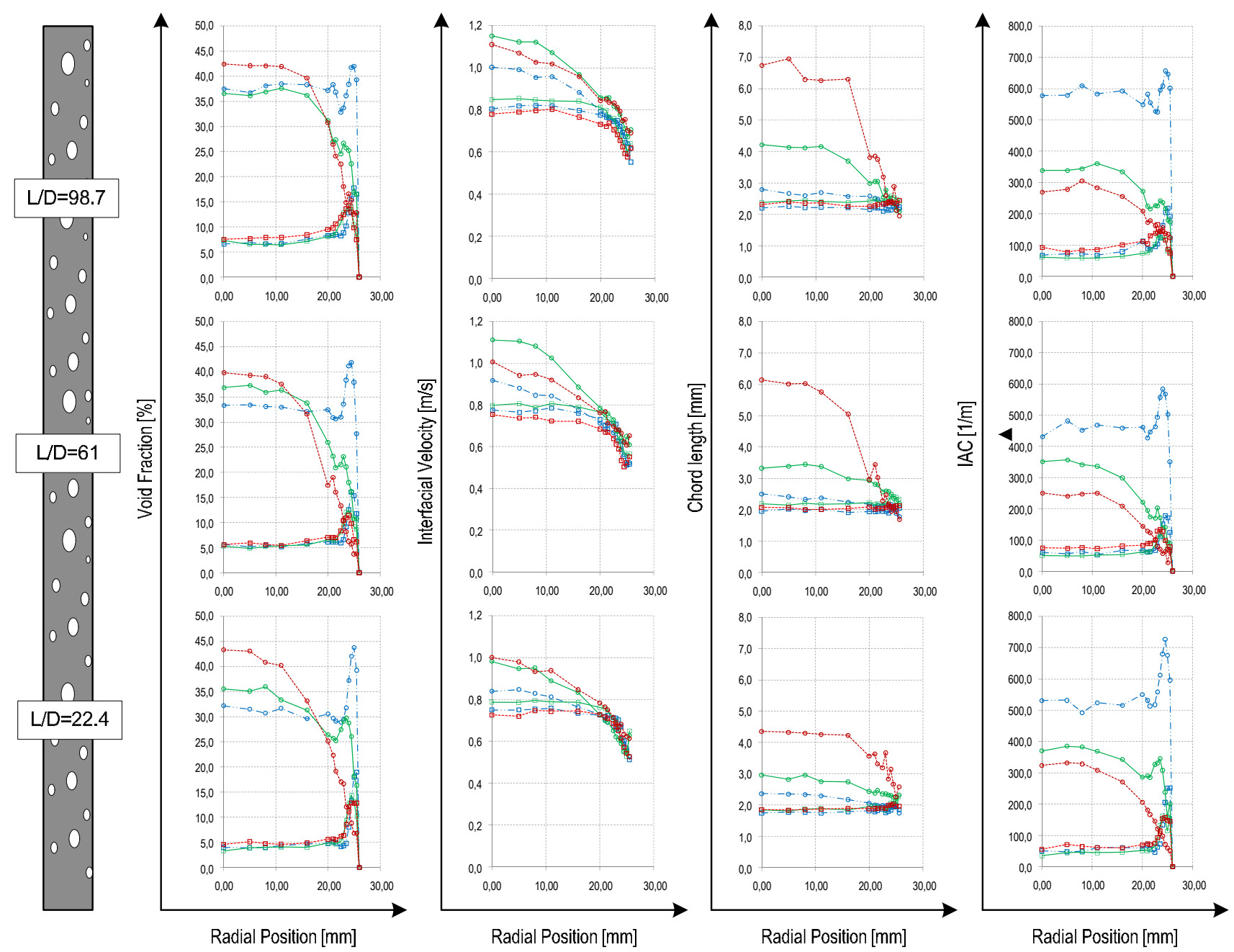

Fig 9. Void fraction, interfacial velocity, Chord length and IAC for $\mathrm{jl}=0.5 \mathrm{~m} / \mathrm{s}, \mathrm{jg}=0.05-0.3 \mathrm{~m} / \mathrm{s}, 15^{\circ}(\mathrm{TC}), 21^{\circ} \mathrm{C}(\mathrm{TA})$ and $37^{\circ}(\mathrm{TH})$. The legend is as follows: $(-\square) \mathrm{jl}=0.5 \mathrm{~m} / \mathrm{s}, \mathrm{jg}=0.05 \mathrm{~m} / \mathrm{s}, \mathrm{TC} ;(-\circ) \mathrm{jl}=0.5 \mathrm{~m} / \mathrm{s}, \mathrm{jg}=0.3 \mathrm{~m} / \mathrm{s}, \mathrm{TC} ;(--) \mathrm{jl}=0.5 \mathrm{~m} / \mathrm{s}$, $\mathrm{jg}=0.05 \mathrm{~m} / \mathrm{s}, \mathrm{TA} ;(-)) \mathrm{jl}=0.5 \mathrm{~m} / \mathrm{s}, \mathrm{jg}=0.3 \mathrm{~m} / \mathrm{s}, \mathrm{TA} ;(-\bullet) \mathrm{jl}=0.5 \mathrm{~m} / \mathrm{s}, \mathrm{jg}=0.05 \mathrm{~m} / \mathrm{s}, \mathrm{TH} ;(-\diamond) \mathrm{jl}=0.5 \mathrm{~m} / \mathrm{s}, \mathrm{jg}=0.3 \mathrm{~m} / \mathrm{s}, \mathrm{TH}$.

- Near to the wall, the interfacial velocity decreases due to the wall influence.

- With liquid superficial velocity less than 2 $\mathrm{m} / \mathrm{s}$ and wall peak distribution the increase of $j g$ has a little influence on the gas velocity profile and void fraction profile for TC conditions. In some TA and TH cases the increase of $j g$ may cause the change to a transition or core peak distribution.

- The gas velocity increases substantially when large bubbles appear in the flow.

- Wall peak is located at one bubble diameter from the wall, but this distance seems to increase slightly with the velocity of the fluid and a greater void fraction.

- Hottest liquid produces an increasing of the magnitude of void fraction in the core peak scenarios.

- The bubble size at the top of the pipe increases with the hottest liquid, then IAC has reduced values in comparison to the case with coldest liquid.

\section{LDA methodology}

The Laser Doppler Anemometer, or LDA, is a widely accepted tool for fluid dynamic investigations in gases and liquids and has been used as such for more than three decades. It is a well-established technique that gives information about flow velocity. It is non-intrusive principle and directional sensitivity make it very suitable for applications with reversing flow, chemically reacting or high-temperature media and rotating machinery, where physical sensors are difficult or impossible to use.

LDA measurements have been taken in top port $(\mathrm{L} / \mathrm{D}=97.5)$, where fully developed flow is achieved.

All experimental data sets with LDA (turbulence intensity and liquid velocity) were realized in the same experimental conditions of corresponding experimental data using conductivity probes. 

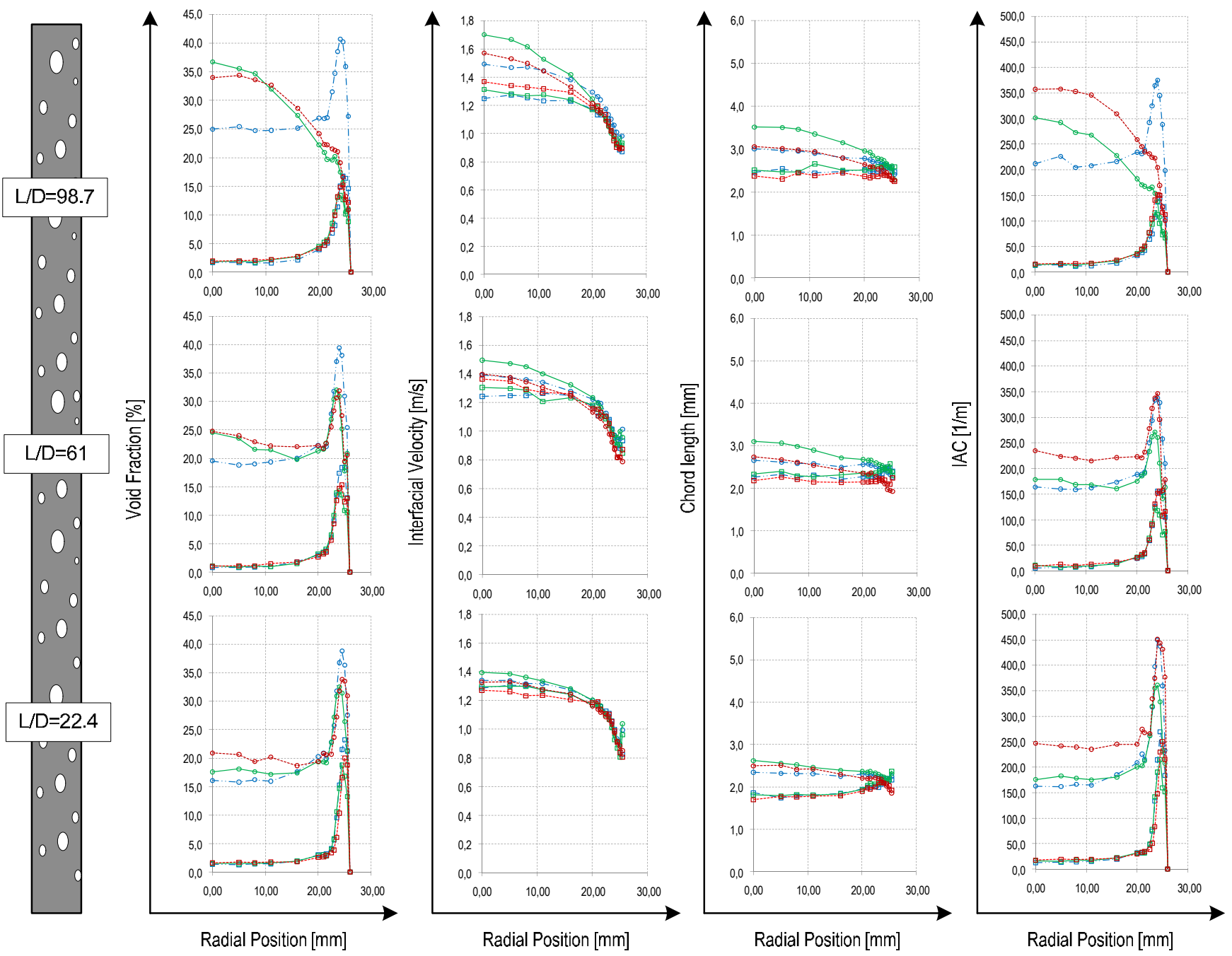

Fig 10. Void fraction, interfacial velocity, Chord length and IAC for $\mathrm{jl}=1 \mathrm{~m} / \mathrm{s}, \mathrm{jg}=0.05-0.3 \mathrm{~m} / \mathrm{s}, 15^{\circ}(\mathrm{TC}), 21^{\circ} \mathrm{C}$ (TA) and $37^{\circ}(\mathrm{TH})$. The legend is as follows: $\left.(-)^{-}\right) \mathrm{jl}=1 \mathrm{~m} / \mathrm{s}, \mathrm{jg}=0.05 \mathrm{~m} / \mathrm{s}, \mathrm{TC} ;(-\circ) \mathrm{jl}=1 \mathrm{~m} / \mathrm{s}, \mathrm{jg}=0.3 \mathrm{~m} / \mathrm{s}, \mathrm{TC} ;(--) \mathrm{jl}=1 \mathrm{~m} / \mathrm{s}, \mathrm{jg}=0.05$ $\mathrm{m} / \mathrm{s}, \mathrm{TA} ;(-)$ jl=1 m/s, jg=0.3 m/s, TA; $(-\bullet) \mathrm{jl}=1 \mathrm{~m} / \mathrm{s}, \mathrm{jg}=0.05 \mathrm{~m} / \mathrm{s}, \mathrm{TH} ;(--) \mathrm{jl}=1 \mathrm{~m} / \mathrm{s}, \mathrm{jg}=0.3 \mathrm{~m} / \mathrm{s}, \mathrm{TH}$.

The presence of the bubbles leads to increased noise levels compared with LDA in single phase flows. The higher noise levels lead to the occurrence of multiple validations, i.e., the multiple detection of the burst caused by a single particle. This may lead to inaccurate velocity estimates or even outliers. In the processing program the effect was handled by first rejecting velocity realizations with:

$$
\left|V_{i}-\bar{V}_{l}\right|>4 \sigma
$$

Being $\sigma$ the standard deviation of the signal. The next data processing steps are related with the velocity bias correction. In a time varying flow the instantaneous data rate is generally correlated with the instantaneous liquid velocity. As a result, the higher velocities are usually over-represented in the time signal and the velocity moments are biased if simple arithmetic averaging is used (velocity bias). Previous work has shown the importance of velocity bias correction for bubble column flow experiments [17]. The velocity bias correction is performed by so-called 2D+weighting: inversely weighing the data with the velocity [18]. Since only two components are known, the magnitude of the third component is estimated from the variance of the second component: the weighting factor is:

$$
w=\frac{1}{\sqrt{V_{x}^{2}+V_{z}^{2}+\left(\frac{d_{m}}{l_{m}}\right)^{2} \cdot V_{z}^{\prime 2}}}
$$

With $d_{m} / l_{m}$ as the diameter-to-length ratio of the ellipsoidal measurement volume, and $V_{x}$ and $V_{z}$ as the lateral and vertical liquid velocity components. The use of only two components is justified since the magnitude of the vertical and lateral fluctuations will be close. Based on the fluctuating component of the velocity, it is possible to define several parameters of interest for the study of turbulence. In particular, the relative turbulence intensity is defined as the ration of the root mean square value of the fluctuation velocity referred to the mean velocity of the flow [19]: 


$$
I=\frac{u_{r m s}^{\prime}}{\bar{u}}=\frac{\sqrt{\frac{1}{3}\left(u_{x}^{\prime 2}+u_{y}^{\prime 2}+u_{z}^{\prime 2}\right)}}{\bar{u}}
$$

Where $u_{r m s}^{\prime}$ is called the absolute turbulence intensity.

The turbulence kinetic energy is defined as [20]

$$
\mathrm{k}=\frac{1}{2}\left(\overline{\mathrm{u}_{\mathrm{x}}^{\prime 2}}+\overline{\mathrm{u}_{\mathrm{y}}^{\prime 2}}+\overline{\mathrm{u}_{\mathrm{z}}^{\prime 2}}\right)
$$

In order to calculate turbulence intensity we assume $u_{x}^{\prime}=u_{z}^{\prime}$ so with current system we are only able to measure in two directions, and this two magnitudes will be close.

LDA data acquisition is realized at frequency about 100-300 Hz depending on radial position and until 3000 of samples are acquired.

\subsection{Experimental data}

In order to obtain a velocity and turbulence profile, we measure liquid velocity components in axial ( $y$ axis) and radial ( $x$ axis) direction with LDA in 15 diameter pipe radial positions (with and without presence of gas). LDA data sets have been taken at different conditions:

- $\quad$ Superficial liquid velocities $(j l): 0.5,1,2,3$ $\mathrm{m} / \mathrm{s}$.

- $\quad$ Superficial gas velocities (jg): $0,0.05,0.1$, $0.15,0.2,0.3 \mathrm{~m} / \mathrm{s}$.

- Temperatures: $15^{\circ} \mathrm{C}(\mathrm{TC})$ and $37^{\circ} \mathrm{C}(\mathrm{TH})$

- Axial position: $\mathrm{L} / \mathrm{D}=98.7$.

Figures 12 and 13 show the liquid velocity profiles obtained with LDA at different temperatures, shown in Table 3 .

Table 3. Experimental flow conditions for LDA.

\begin{tabular}{|c|c|c|c|c|c|c|c|}
\hline \multirow[b]{2}{*}{ Nrun } & \multicolumn{3}{|c|}{$\begin{array}{c}\mathrm{jl} \\
2[\mathrm{~m} / \mathrm{s}]\end{array}$} & \multicolumn{4}{|c|}{$\begin{array}{c}\mathrm{jl} \\
3[\mathrm{~m} / \mathrm{s}]\end{array}$} \\
\hline & $\begin{array}{c}\text { jg } \\
{[\mathbf{m} / \mathbf{s}]}\end{array}$ & $\begin{array}{c}\alpha \\
{[-]}\end{array}$ & $\begin{array}{c}\mathbf{T} \\
{\left[{ }^{\circ} \mathbf{C}\right]}\end{array}$ & Nrun & $\begin{array}{c}\text { jg } \\
{[\mathbf{m} / \mathbf{s}]}\end{array}$ & $\begin{array}{c}\alpha \\
{[-]}\end{array}$ & $\begin{array}{c}\mathbf{T} \\
{\left[{ }^{\circ} \mathbf{C}\right]}\end{array}$ \\
\hline RunCA & 0.00 & 0.00 & 16.03 & RunDA & 0.00 & & 15.76 \\
\hline Run35 & 0.10 & 0.05 & 15.87 & RunDB & 0.10 & 0.05 & 15.34 \\
\hline Run36 & 0.20 & 0.10 & 16.27 & RunDC & 0.20 & 0.10 & 15.75 \\
\hline RunCB & 0.10 & 0.05 & 36.56 & RunDE & 0.10 & 0.04 & 36.47 \\
\hline Run48 & 0.20 & 0.10 & 36.68 & RunDF & 0.20 & 0.08 & 36.68 \\
\hline Run49 & 0.25 & 0.13 & 36.55 & RunDG & 0.30 & 0.11 & 36.67 \\
\hline
\end{tabular}

\begin{tabular}{|cccc|cccc|}
\hline & \multicolumn{3}{c}{$\mathbf{j l}$} & \multicolumn{3}{c|}{$\mathbf{j l}$} \\
\multirow{2}{*}{ Nrun } & $\mathbf{j g}$ & $\mathbf{0 . 5} \mathbf{[ m} / \mathbf{s}]$ & $\mathbf{\alpha}$ & $\mathbf{T}$ & & & $\mathbf{1}[\mathbf{m} / \mathbf{s}]$ \\
& {$[\mathbf{m} / \mathbf{s}]$} & {$[-]$} & $\left.{ }^{\circ} \mathbf{C}\right]$ & Nrun & $\mathbf{j g}$ & $\mathbf{\alpha}$ & $\mathbf{T}$ \\
{$[\mathbf{m} / \mathbf{s}]$} & {$[-]$} & {$\left[{ }^{\circ} \mathbf{C}\right]$} \\
\hline RunAA & 0.00 & 0.00 & 16.12 & RunBA & 0.00 & 0.00 & 16.23 \\
Run01 & 0.05 & 0.06 & 16.52 & Run18 & 0.05 & 0.05 & 15.00 \\
Run02 & 0.10 & 0.13 & 18.96 & Run19 & 0.10 & 0.09 & 14.65 \\
Run03 & 0.15 & 0.19 & 17.98 & Run20 & 0.15 & 0.12 & 14.53 \\
RunAB & 0.05 & 0.07 & 34.60 & Run29 & 0.05 & 0.05 & 35.83 \\
Run15 & 0.10 & 0.13 & 35.77 & Run30 & 0.10 & 0.08 & 36.47 \\
Run14 & 0.15 & 0.20 & 36.34 & Run31 & 0.15 & 0.13 & 36.52 \\
\hline
\end{tabular}

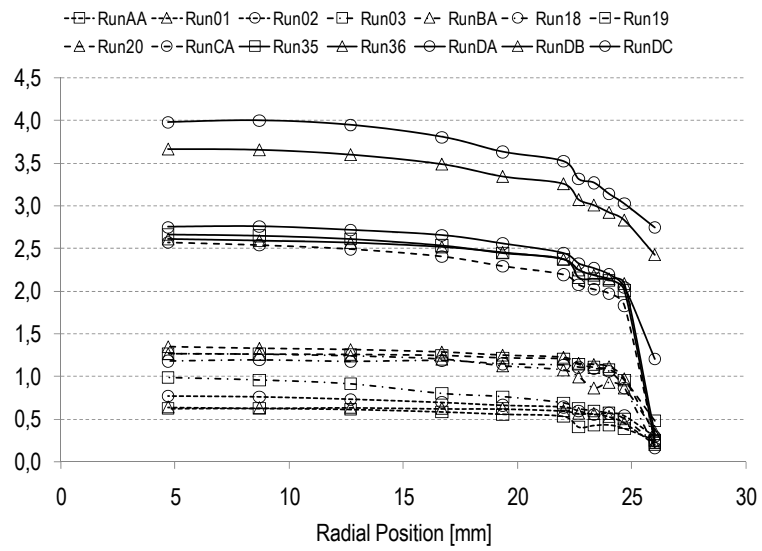

Fig 12. LDA liquid velocity profiles at $15^{\circ}$ (TC).

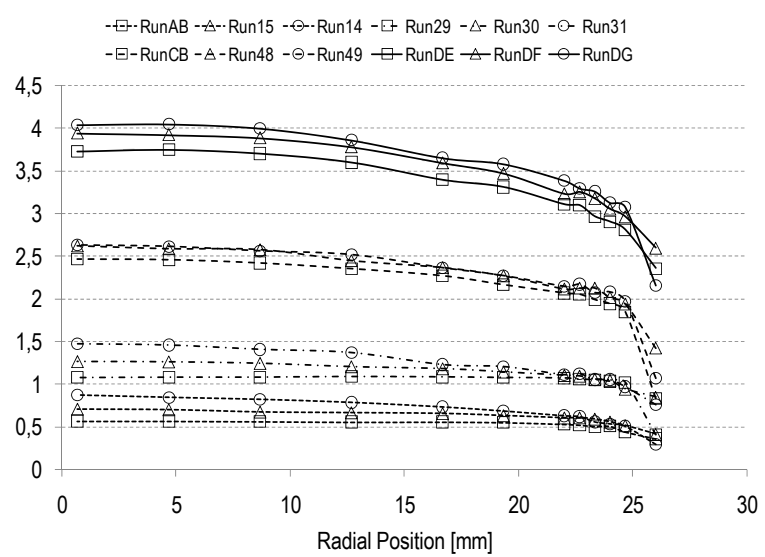

Fig 13. LDA liquid velocity profiles at $37^{\circ}(\mathrm{TH})$.

Figures 14 and 15 show turbulence intensity obtained from processed LDA data at different temperatures.

Theoretically we should observe a wall-peak behaviour (turbulence intensity tends to zero near to the wall of the pipe) but due to LDA measurement volume control (above 1-1.5 mm length) we have not enough precision to validate the measurements in that zone near to the wall.

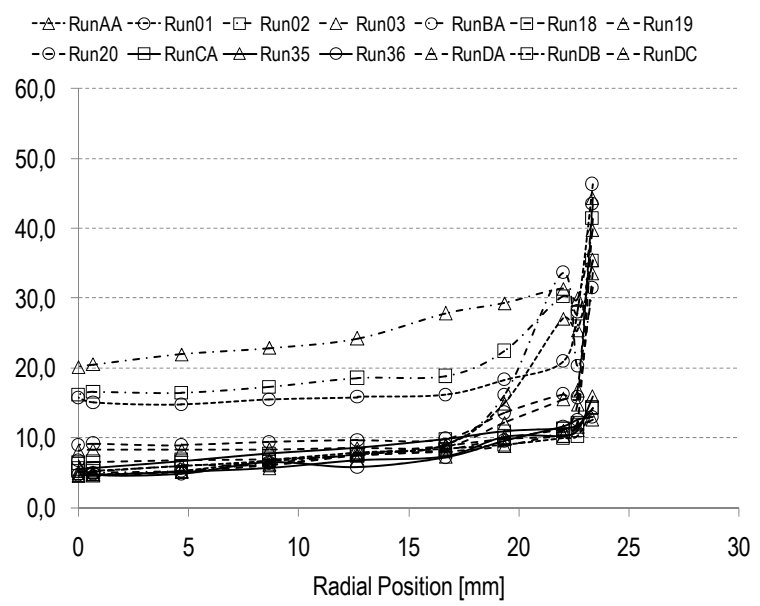

Fig 14. LDA Turbulence intensity profiles at $15^{\circ}$ (TC). 


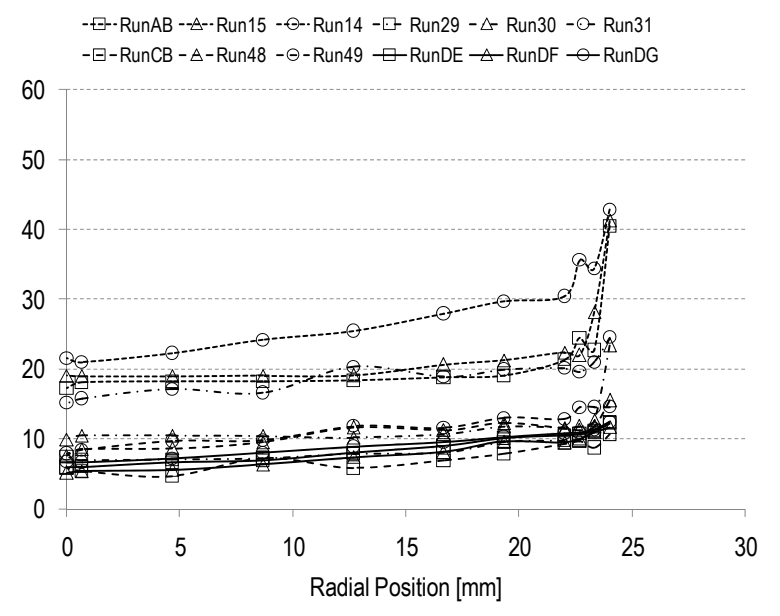

Fig 15. LDA Turbulence intensity profiles at $15^{\circ}(\mathrm{TC})$.

We can observe the effect of increasing gas phase and velocity in zones near to center of the pipe: increasing the amount of gas, turbulence intensity is higher in the center of the pipe due to the alteration caused by the bubbles presence.

Increment of turbulence not seems to be proportional to the amount of gas: from single phase to $j g=0.05$ (about $5 \%$ of void fraction) the turbulence intensity at the center of the tube increase, but further gas increments seem to increase the turbulence intensity in a more moderate way. For void fractions above $25 \%$, the increase of the gas does not seem to increase the turbulence intensity.

For low liquid velocity, less than $1 \mathrm{~m} / \mathrm{s}$, the presence of bubbles seems to decrease the turbulence intensity near the wall. It can be observed in figures 17 and 18 .

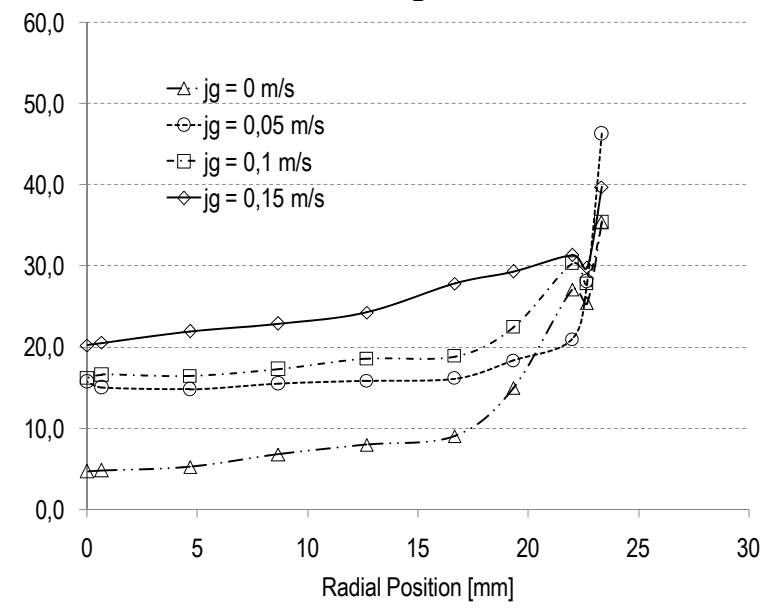

Fig 16. LDA Turbulence intensity profiles at $j l=0.5 \mathrm{~m} / \mathrm{s}, 15^{\circ}$ (TC).

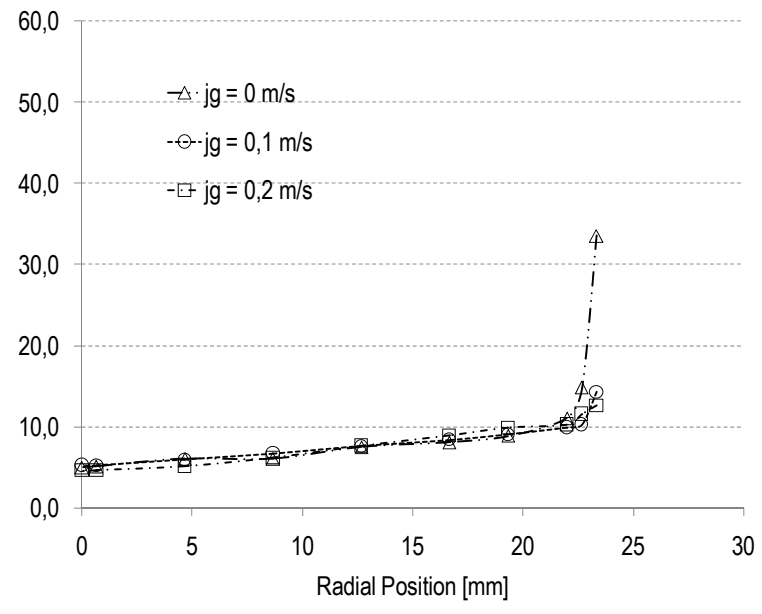

Fig 17. LDA Turbulence intensity profiles at $j l=3 \mathrm{~m} / \mathrm{s}, 15^{\circ}$ (TC).

Same behaviour is observed for the hot temperatures in Figures 18 and 19, but with few differences: due to lower viscosity of hot water, turbulence intensity profile seems to be more flattened near to the wall.

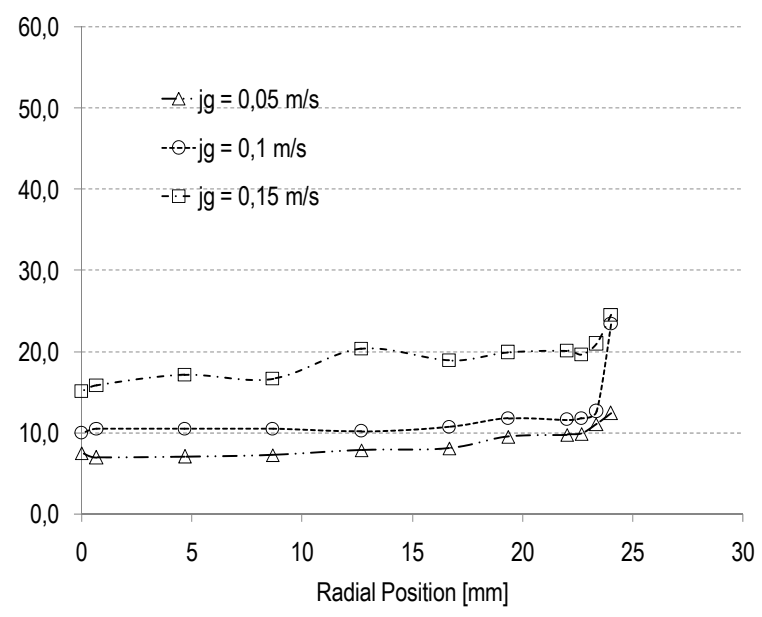

Fig 18. LDA Turbulence intensity profiles at $j l=1 \mathrm{~m} / \mathrm{s}, 37^{\circ}$ (TH).

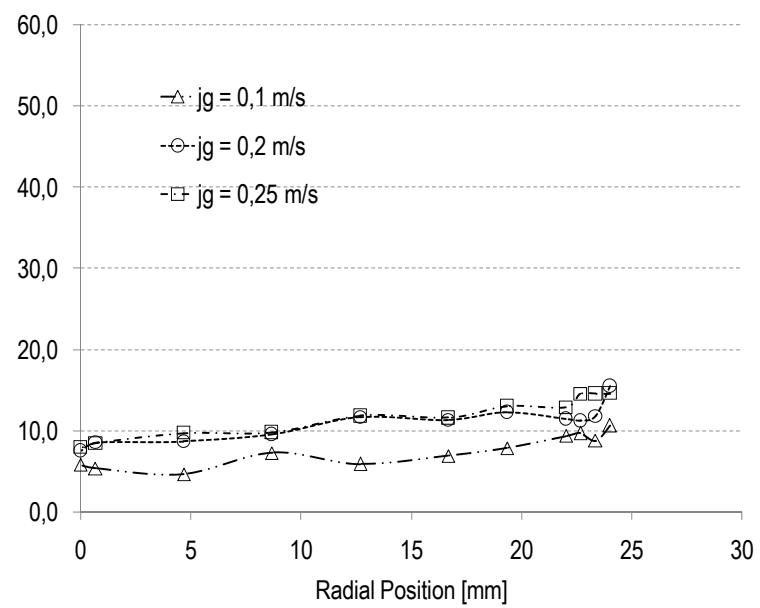

Fig 19. LDA Turbulence intensity profiles at $j l=2 \mathrm{~m} / \mathrm{s}, 37^{\circ}(\mathrm{TH})$.

At $j l=1 \mathrm{~m} / \mathrm{s}$ Figure 20 shows how at $\mathrm{jl}=1 \mathrm{~m} / \mathrm{s}, 5 \%$ void fraction and variation of temperature affect to velocity profile: turbulence intensity caused by bubbles makes velocity profile more flattened near the wall. It can be 


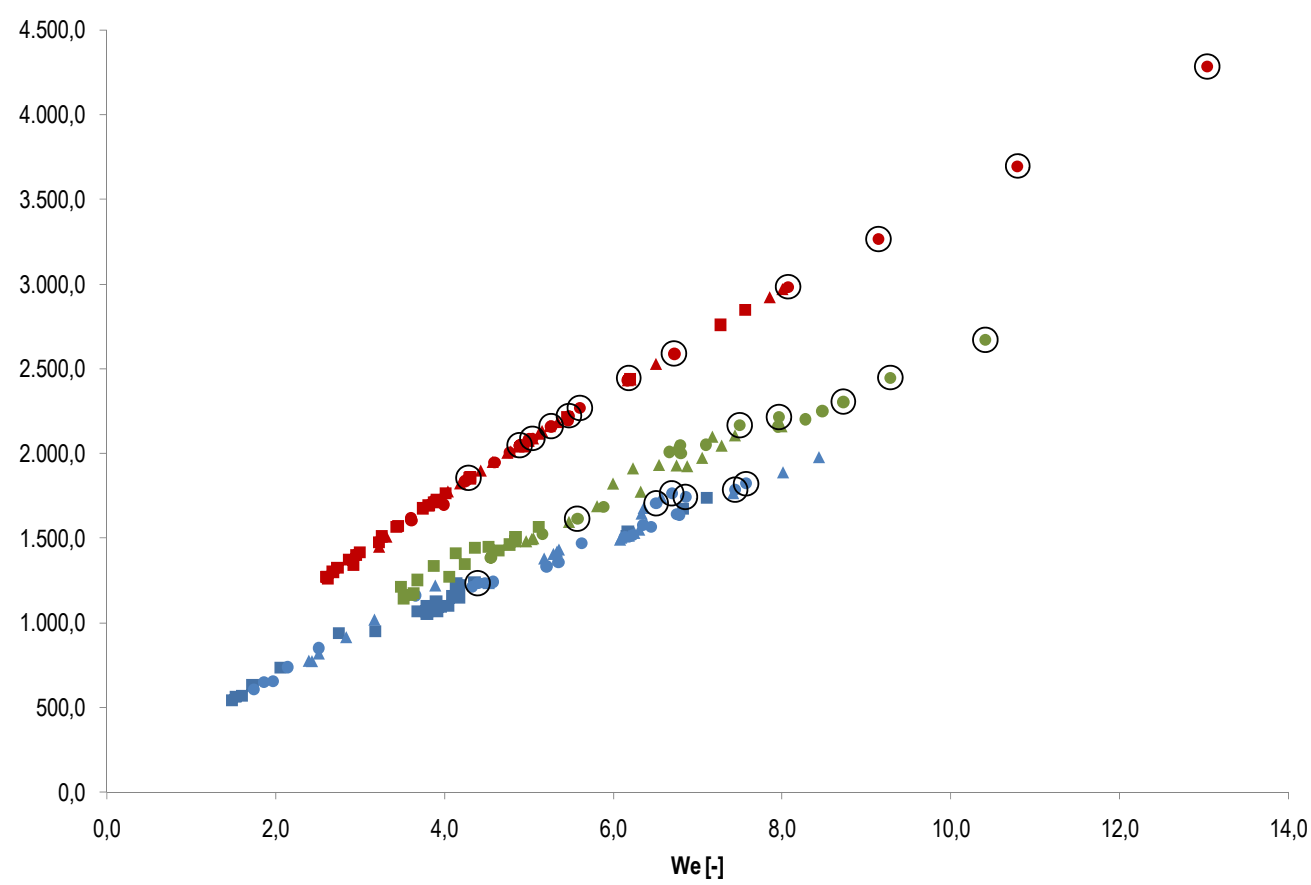

Fig 21. Map of Reynolds and Weber numbers. Liquid velocities are ranged from 0.5 to $3 \mathrm{~m} / \mathrm{s}$ whereas gas concentration were $4 \%$ to $36 \%$. The different symbols show measurements obtained for different axial location, and the different colour show measurements obtained at different temperature. The legend is as follows: for all jl and jg ranges, ( $\mathrm{D}) \mathrm{L} / \mathrm{D}=22.4$ and

TC, $\left(\left(^{\Delta}\right) \mathrm{L} / \mathrm{D}=61\right.$ and TC, $\left({ }^{\bullet}\right) \mathrm{L} / \mathrm{D}=98.7$ and TC, $(\bullet) \mathrm{L} / \mathrm{D}=22.4$ and TA, $\left({ }^{\star}\right) \mathrm{L} / \mathrm{D}=61$ and TA, $(\bullet) \mathrm{L} / \mathrm{D}=98.7$ and TA,

( $) \mathrm{L} / \mathrm{D}=22.4$ and $\mathrm{TH},(\Delta) \mathrm{L} / \mathrm{D}=61$ and $\mathrm{TH},(\bullet) \mathrm{L} / \mathrm{D}=98.7$ and $\mathrm{TH},(\mathrm{O})$ transition or core peak distribution.

observed the major effect of flattened profile at high temperature: in this case the increase is due to combination of less liquid phase density and bubble agitation.

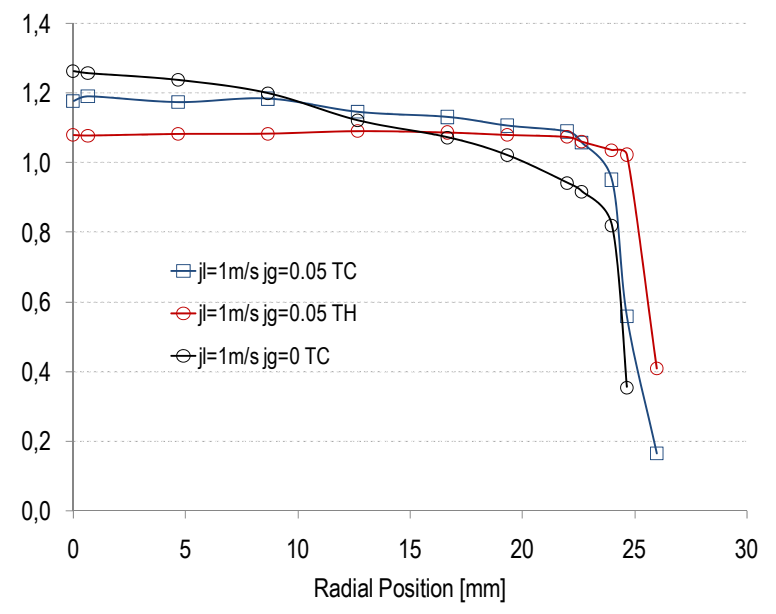

Fig 20. LDA Velocity profiles at $j l=1 \mathrm{~m} / \mathrm{s}, j g=0.05 \mathrm{~m} / \mathrm{s} 15^{\circ}(\mathrm{TC})$ and $37^{\circ}(\mathrm{TH})$ and $j l=1 \mathrm{~m} / \mathrm{s} ; j g=0 \mathrm{~m} / \mathrm{s} 15^{\circ}(\mathrm{TC})$.

Figure 21 shows a map of the Reynolds and Weber numbers all experimental data considered in this paper. The solid markers show measures at different conditions and different axial point measurement whereas empty markers show either transition or core peak distributions. Only measures which shows core peak distribution in $\mathrm{L} / \mathrm{D}=98.7$ are marked, so we can assure fully developed flow in this stage.
Criteria assumed to consider transition or core peak distribution has been the percentage of slug bubbles in the center of the pipe. If slug bubble number is above $1 \%$ of the total computed bubbles transition or core peak distribution is considered.

It can be observed that a critical Weber number above which the core peak distribution appear, as it shows Figure 21. Above $\mathrm{We}=4$ for current experimental conditions, even when liquid temperature changes, the transition to the core peak from wall peak is initiated.

\section{Error analysis}

In order to validate the experiments carried out with foursensor conductivity probes we have compared the processed air flow data (using calculated interfacial velocity and mean void fraction) against air flow meter mean values with a $\pm 15 \%$ relative error, Figure 22 .

Validation of velocity profiles obtained with LDA and void fraction obtained from four-sensor conductivity probes at same experiment conditions through comparison of superficial liquid velocity measured with water flow meter. Errors inside $\pm 10 \%$ limits have been obtained.

\section{Conclusions}

A methodology to measure the main magnitudes that characterize the two-phase flow is presented in this paper. Local interfacial area concentration, void fraction, chord 
length, interfacial velocity and bubble size distribution for air-water flow through a vertical pipe are experimentally studied in order to provide an experimental database where temperature changes and transition effect have been taken into account. Experimental data from four-sensor conductivity probes and LDA system at different temperatures are presented in this paper to provide information about phase distribution inside the pipe, liquid and gas. The effects of temperature variation and turbulence over liquid phase velocity profile have been studied. Finally, experimental data has been evaluated to identify the transition from wall to core peak, using dimensionless Weber and Reynolds numbers.

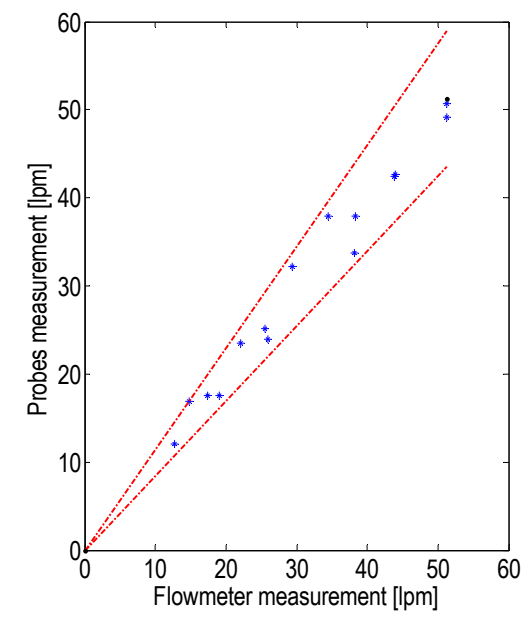

Fig 22. Example of error check out using air flow meter, case $j l=1 \mathrm{~m} / \mathrm{s}, j g=0.05-0.3 \mathrm{~m} / \mathrm{s}$ and TC.

\section{Acknowledgements}

The authors sincerely thank the Spanish Science and Innovation Ministry for funding the project belonging to the Plan Nacional I+D, ENE2010-21368-C02-02 and ENE2010-21368-C02-01.

\section{References}

1. J.M. Delhaye, P.Bricard, J. Nucl. Engng. Des. 151, pp. 65-77 (1994)

2. I. Kataoka, M. Ishii, A. Serizawa, Int. J. Multiphase Flow, 12-4, pp.505-529 (1986)

3. T. Hibiki, M. Ishii, Int. J. Heat Mass Transfer, 42, pp.3019-3035 (1999)

4. Q. Wu, M. Ishii, Int. J. Multiphase Flow, 25, 1, pp.155-173 (1999)

5. T. Hibiki, M. Ishii, Z. Xiao, Int. J. Heat Mass Transfer, 44, pp.1869-1888 (2001)

6. S. T. Revankar, M. Ishii, Int. J. Heat Mass Transfer, 36-12, pp.2997-3007 (1993)

7. S. Kim, X. Fu Y., X. Wang, M. Ishii, Int. J. Heat and Mass Transfer, 43, 4101-4118 (2000)

8. T. Hibiki, M. Ishii, Z. Xiao, Int. J. Heat Mass Transfer, 44, pp.1869-1888 (2001)

9. T. Hibiki, T. Hazuku, T. Takamasa, M. Ishii, AIAA Journal, 47, 5, pp. 1123-1131 (2009)
10. Y. Taitel, D. Bornea, E. A. Dukler, AIChE J., 26, 345-354 (1980)

11. A. Serizawa, I. Kataoka, Phase distribution in twophase flow, Transient Phenomena in Multiphase Flow, (Hemisphere, Washington DC, pp.179-224, 1988)

12. I. Zun, Transition from wall void peaking to core void peaking in turbulent bubbly flow, Transient Phenomena in Multiphase flow (Hemisphere, Whashington DC, pp.225-245, 1988)

13. S. Mendez-Diaz, R. Zenit, S. Chiva, J. L. MuñozCobo, S. Martinez-Martinez, Int. J. Multiphase Flow, 43, pp. 56-61 (2012)

14. M. Ishii, Thermo-fluid Dynamic Theory of Twophase Flow (Eyrolles, Paris, 1975)

15. X. Shen, Y. Saito, K. Mishima, H. Nakamura, Int. J. Multiphase Flow, 31, pp. 593-617 (2005)

16. M. Ishii, T. Hibiki, Thermo-fluid Dynamics of TwoPhase Flow, Springer (2007)

17. W.K. Harteveld, R.F. Mudde, H. Van den Akker, CJChE, 81, pp. 389-394 (2003)

18. M.J. Tummers, Investigation of a turbulent wake in an adverse pressure gradient using laser Doppler anemometry (Ph.D. Thesis, Delft University of Technology, The Netherlands, 1999)

19. S. Turns, Introduction to Combustion (McGraw-Hill Publishing Co, 2000)

20. D. C. Wilcox, Turbulence Modeling for CFD (DWC Industries, 2006) 